\title{
STUDY ON INTEGRATING ACCOUNTING IN THE INFORMATION SYSTEM OF THE ORGANIZATION
}

\author{
Alina-Teodora CIUHUREANU \\ "Nicolae Bălcescu" Land Forces Academy, Sibiu, Romania \\ alinaciuhureanu@yahoo.com
}

\begin{abstract}
In order to gain power in an ever-changing economy, in diversified markets, the organization must have an up-to-date information system that enables managers to get a detailed understanding of the organization's status and to obtain what is needed to manage - the information. Starting from these premises, the empirical research presents the components of the information system. One of the main contributions, however, is to customize the opinions of the specialists and to create a logical scheme on the accounting information system. Moreover, through selective research, the article analyzed the managers' interest in accounting information and its integration into the information system of the organization.
\end{abstract}

KEYWORDS: accounting information, financial statements, financial constructions, information system, management

\section{Introduction}

When talking about organization, management, and not only, all those involved are connected to each other through information, which forms a communication network.

Taking into account the specialists' approaches, the leading role of the information system resides, from the management perspective, in collecting the necessary information for decision making, building a database for economic modeling, measuring the intensity of connections in the management space, analyzing the malfunctions, taking the measures to solve them (Domokos, 1999). The information system is made up of several interdependent components - which, in fact, come from the definition of the information system, support the specialists (Nicolescu and Verboncu, 1999). These are: data and information, information circuits and flows, information procedures and means of handling information. From a structural point of view, the information system of the organization is made up of several sub-systems (see also Tुugui, 2002) presented in Figure no. 1. 


Strategic
level
Management
level
Level of
knowledge
Processing

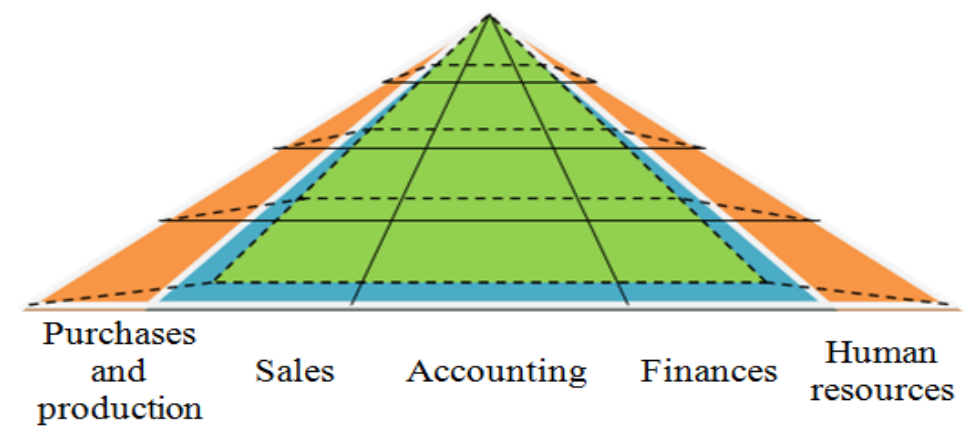

Figure no. 1: Structure of the organization's information system (Source: processing according to the bibliographic references)

Certainly, each of these sub-systems has the place, role and specific importance in management. However, we consider that to a greater or lesser extent all are based at a certain point on the accounting information, used either in "raw" format or in "processed" format.
2. The Accounting Information System - the Logical Scheme

The accounting information system is a means by which the gross accounting information (the data) relating to a business is identified, measured, recorded, presented and capitalized in such a way that it can be transmitted to those interested (Figure no. 2).

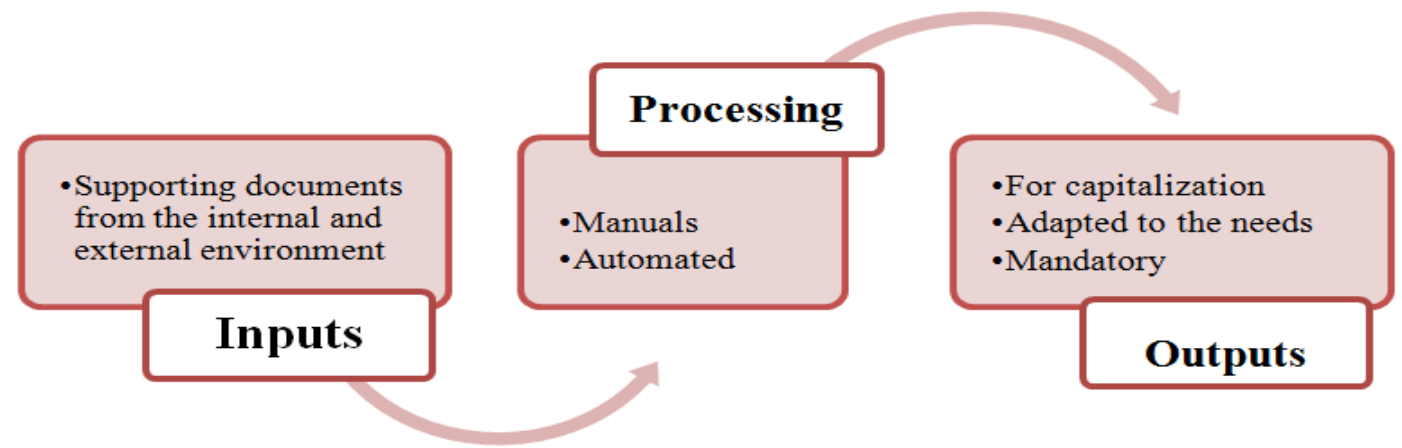

Figure no. 2: Processing circuit

(Source: own processing)

Like the general information system, the accounting system also has the same components, namely data and information, information circuits and flows, information procedures and means of handling information, including the creation, collection, storage, processing of data, transmission and use of information to achieve management functions. The data used comes from the internal environment for example, expenditures incurred, pluses or minuses in inventories, hours worked, consumption etc. found in all the activities carried out by the organization, these being transposed in the supporting documents and so on - and from the external environment - from trading partners, financial institutions, state bodies, associates/ shareholders etc. - each of which being in the form of supporting documents, studies, reports.

External sources of data and information can also be represented by legislative regulations, mandatory annual financial statements of other entities, internal situations of other entities (journals, registers, verification balance, specific balances etc.), the The National Tax Administration Agency's website (ANAF), the National Institute of Statistics 
(NIS) web pages, the Regional Directorates of Statistics (DRS), the websites of the Chambers of Commerce, Industry and Agriculture (CCIA), providing management opportunities to use in management for decision-making.

The processing of data leads to the obtaining accounting information and can be elaborated either from the perspective of the obligation or according to its own needs for capitalizing the accounting information, by using a specific language and the rules that allow the coding and decoding of data, ensuring an orderly and intelligible representation of the economic and financial reality (Brabete, 2011).

Regarding the circuit and flow of accounting information, it is recommended that they be set to avoid various deficiencies such as distortion, filtering, redundancy, short-circuiting, overloading, lack of efficiency, or that they be as direct and short as possible, with minimal downsides in the intermediary entries, avoiding, as far as possible, their prolongation downstream and/or upstream of the targeted information beneficiaries. Information procedures specific to the accounting information system can be translated into the accounting policy manual and/or accounting procedures (Ciuhureanu, 2014; Ciuhureanu, 2016). It is necessary that they establish: the information carriers used, the sequence of the information processing, the operations to be applied to the information; the models and calculation formulas used, means used in the collection, storage, processing, transmission of information representing the technical support of the accounting information system (Nicolescu and Verboncu, 1999). Starting from the opinions identified by the study of the specialized literature regarding the informational system and by the specific transposition in the field of accounting, we present in Figure no. 3 the logical scheme of the accounting information system.

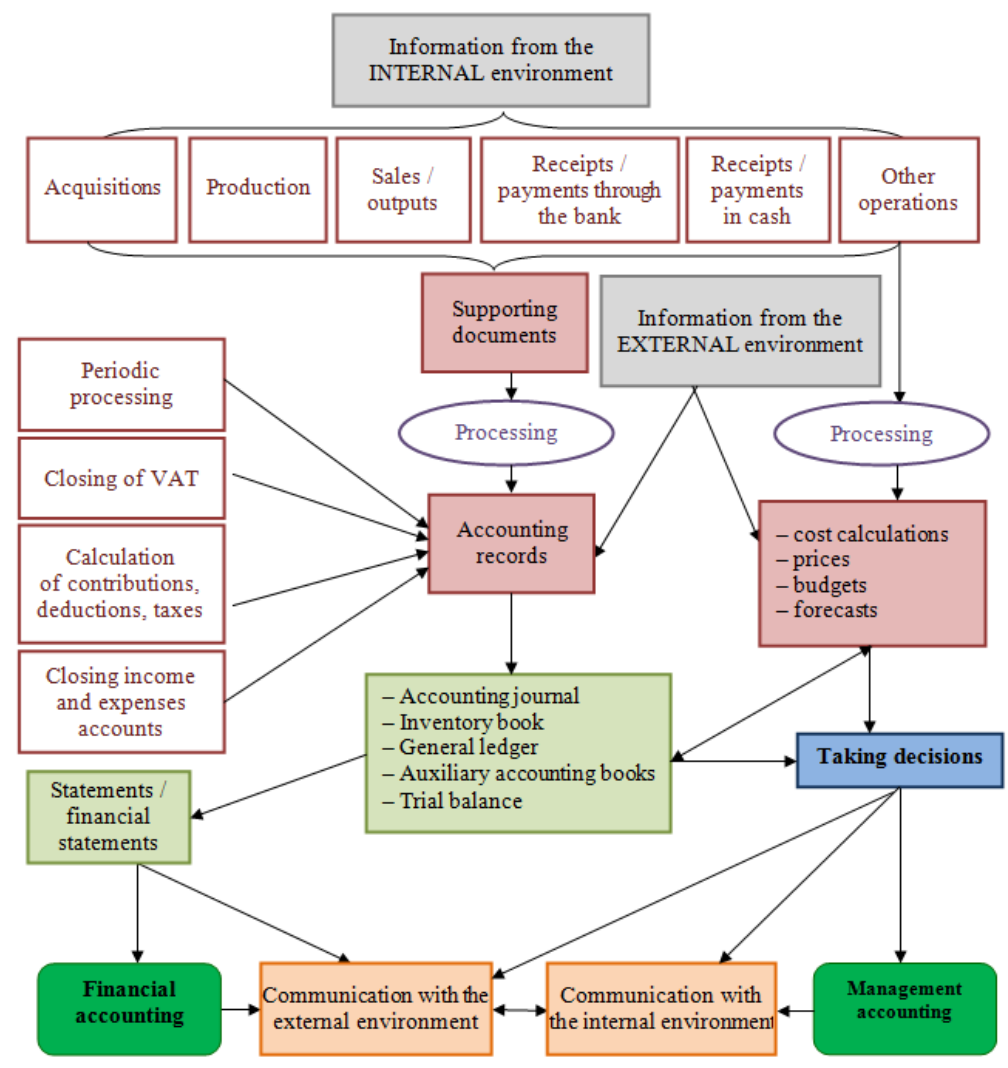

Figure no. 3: Accounting information system - logical scheme (Source: own processing) 


\section{Methodology of Selective Research}

Starting from the above-mentioned aspects and emphasizing that accounting is a component of the general information system, but having its own logical components and logic, the objective of the selective research is to identify the general interest of managers in accounting information. Following previous studies, but also in the light of the experience gained as a practitioner in the accounting field, two hypotheses were formulated:

- Main hypothesis $\boldsymbol{I P}_{5}$ - Managers/ administrators are aware, act and capitalize the accounting information on an average level.

- Secondary hypothesis $\boldsymbol{I S}_{5}-$ The extent to which managers/administrators are aware, act and capitalize the accounting information is influenced by the entity's category and subject of activity.

In order to achieve the proposed goal, we used the questionnaire as a tool, the v77 variable - "Please evaluate with a score from 1 (the lowest) to 10 (the highest), the level at which your entity's managers" being of 10-stage multiple choice/semantic differential. The survey was carried out on a sample of 301 economic entities active in the Center Region (non-probability random sampling) using the direct research method (Cătoiu, 2009).

\section{Results and Conclusions of the Selective Research}

The information obtained from the processing of the data collected for the above mentioned variable is presented in Table no. 1

Interest in accounting information

\begin{tabular}{|l|c|}
\hline \multicolumn{1}{|c|}{ Valid 301 Missing 0 } & Score \\
\hline A. Are aware of the opportunities offered by accounting information & 8.28 \\
\hline B. Act to mitigate the effects of limits on the use of accounting information & 6.75 \\
\hline C. Valuate the accounting information in the entity's management & 7.90 \\
\hline General score: & 7.64 \\
\hline
\end{tabular}

Analyzing the obtained marks, we note that the highest score, namely 8.28 (on a scale from 1 to 10 ), was obtained with regard to the assertion regarding the management awareness of the opportunities offered by the accounting information for management, which determines us to conclude that the managers/administrators of the investigated entities are aware of the usefulness of accounting information in the decision-making process and that the managerial act must also be based on the accounting information. Although we noticed a high level of awareness, the score for the "capitalization of accounting information" option is lower (7.90), but the difference is not significant. We can also see a high score in this respect as well, given that, as we will present during the research, we have found many times that the accounting information is not capitalized. All we have to do is ask what recovery means if information is not used for a minimum of indicators that will at least allow for the analysis of liquidity, solvency, indebtedness, payment or collection rates, knowledge of costs. Perhaps capitalization is viewed from the point of view of mandatory reporting, which shows the connection of accounting information to taxation. Regarding the actions for diminishing the limits of the use of accounting information, a score of 6.75 was calculated, which shows that there are such actions but at a limited level.

In order to have a more detailed view, within the objective, we proceeded to associate with the category of entities and the scope of activity (v77 according to v2, v77 according to v3), the calculation being 
performed and weighted (depending on the weight of each category or domain in the total sample) so as not to distort the information. The obtained results are presented in Table no. 2.

Table no. 2

Associations of interest in accounting information according to the category of the entity and the field of activity

\begin{tabular}{|c|c|c|c|c|c|}
\hline Interest & \multicolumn{4}{|c|}{ Category / Field } & $\begin{array}{l}\text { Weighted } \\
\text { score }\end{array}$ \\
\hline \multirow{4}{*}{$\begin{array}{c}\text { are aware of the opportunities } \\
\text { offered by accounting information }\end{array}$} & micro & small & medium & big & \multirow{2}{*}{$\begin{array}{c}\text { Category: } \\
7.80\end{array}$} \\
\hline & 7.21 & 8.13 & 8.46 & 9.32 & \\
\hline & commerce & industry & services & agriculture & \multirow{2}{*}{ Field: 8.43} \\
\hline & 8.25 & 9.03 & 8.26 & 7.58 & \\
\hline \multirow{4}{*}{$\begin{array}{c}\text { act to mitigate the effects of limits } \\
\text { on the use of accounting } \\
\text { information }\end{array}$} & micro & small & medium & big & \multirow{2}{*}{$\begin{array}{c}\text { Category: } \\
5.80\end{array}$} \\
\hline & 4.32 & 6.59 & 7.98 & 8.12 & \\
\hline & commerce & industry & services & agriculture & \multirow{2}{*}{ Field: 6.67} \\
\hline & 6.65 & 8.26 & 5.95 & 6.15 & \\
\hline \multirow{4}{*}{$\begin{array}{l}\text { valuate the accounting information } \\
\text { in the entity's management }\end{array}$} & micro & small & medium & big & \multirow{2}{*}{$\begin{array}{c}\text { Category: } \\
7.25\end{array}$} \\
\hline & 6.21 & 7.98 & 8.52 & 8.89 & \\
\hline & commerce & industry & services & agriculture & \multirow{2}{*}{ Field: 8.48} \\
\hline & 8.24 & 9.19 & 8.41 & 5.76 & \\
\hline Score for category & 5.91 & 7.57 & 8.32 & 8.78 & 7.64 \\
\hline Score for field & 7.71 & 8.83 & 7.54 & 6.50 & 7.64 \\
\hline
\end{tabular}

After data processing, as expected, we find that large and industry entities have the highest scores. We note the 9.32 score on opportunities awareness by large entities and 9.03 for the same option, but for the industry field. From the same perspective of awareness, at the opposite pole are micro entities (score - 7.21) and entities in agriculture (score - 7.58). If we look at the differences between the two poles, we can see that they are not very high, the values being 2.11 points for the category and 1.45 points for the field. Looking at the results, we note some differences in minus or in addition for all categories of entities between awareness and capitalization: for large entities from 9.32 to 8.89 , the medium ones record a positive difference of 0.14 points (from note 8.46 for awareness to 8.52 for capitalization), small entities are distinguished by a difference of 0.15 points in minus between the two scores and for micro-entities we distinguish a difference of 1 point in minus, this category being actually the one for which we calculated the greatest difference.

Analysis by field of activity highlights that agriculture has the highest negative difference between the two options (1.82 points). Interestingly, for the industry and service sectors, the differences between the scores are positive without having high values, which determines us to appreciate that the information is being capitalized, even though they are not aware of the importance, under the pressure of external factors (shareholders/potential investors, customers, suppliers, state bodies requests etc.) or professional accountants proceed on their own initiative.

A decrease in scores compared to the other options, regardless of category or field of activity, is noted for "acts to mitigate the effects of limits ...", which ranges from 8.12 (large entities) to 4.32 (micro entities) and 8.26 (industry) 5.95 (services). It is clear that the identification of action paths and implementation is more difficult, either in terms of potential costs if we are talking about continuous training or information technology, or because of the low interest in these lines of action, unfortunately applying the principle "this is fine, too". 
The comparative analysis of the weighted and unweighted scores leads to the revealing of some significant differences, presented in Table no. 3 .

Table no. 3

Comparison score/weighted score

\begin{tabular}{|c|c|c|c|c|}
\hline Valid 301 & Missing 0 & Score & $\begin{array}{l}\text { Weighted score } \\
\text { on category }\end{array}$ & $\begin{array}{c}\text { Weighted } \\
\text { score on field }\end{array}$ \\
\hline \multicolumn{2}{|c|}{$\begin{array}{l}\text { A. Are aware of the opportunities offered by accounting } \\
\text { information }\end{array}$} & 8.28 & 7.80 & 8.25 \\
\hline \multicolumn{2}{|c|}{$\begin{array}{l}\text { B. Act to mitigate the effects of limits on the use of } \\
\text { accounting information }\end{array}$} & 6.75 & 5.80 & 6.51 \\
\hline \multicolumn{2}{|c|}{$\begin{array}{l}\text { C. Valuate the accounting information in the entity's } \\
\text { management }\end{array}$} & 7.90 & 7.25 & 8.16 \\
\hline \multicolumn{2}{|l|}{ General score: } & 7.64 & 7.64 & 7.64 \\
\hline
\end{tabular}

Thus, the awareness of the opportunities recorded a weighted score of 8.25 compared to 7.80 and 8.25 in the unweighted version, which denotes the influence of the categories of economic entities and the field of activity. Regarding the diminution of the effects of the limitations on the use of accounting information, we have calculated a weighted score of 5.80 and 6.51 depending on the field of activity, distinguishing again the difference compared to the unweighted score. Similar situation is also identified for the option on the capitalization of the accounting information (7.25 - category, 8.16 - field of activity compared to 7.90). The overall conclusion drawn from these results is that the field of activity and the category of entities have a direct influence on opinion, capitalization and actions to eliminate the limits.

We can assume that the main hypothesis advanced at the beginning of the research $\left(\boldsymbol{I P}_{5}-\right.$ Managers/administrators are aware, act and valorize on an average level the accounting information) is invalid, the overall level being high while the secondary hypothesis $\left(I S_{5}-\right.$ The degree to which managers/administrators are aware, act and exploit the accounting information is influenced by the entity's category and object of activity) is confirmed. This is the opinion of the respondents and, considering that the research tool was confidential (as the questionnaire shows, there are no operational variables that require specific identification data of the entity or respondent), we want to believe that the answers were sincere. We underline again that these hypotheses were formulated on the basis of personal experience, based on participation in various meetings with specialists/professionals who have another opinion.

\section{Final conclusions}

Accounting information, through multiple uses, must be integrated into the organization's information system, thereby contributing to generating various financial or non-financial constructions. Whether it's financial statements, evaluation, strategy or policy development documents, setting goals, communicating with business partners, satisfying owners' interests, taking investment decisions, financing, etc., an important contribution to all of them is brought by the information generated through financial accounting and management accounting. 


\section{REFERENCES}

Brabete, V. (2011). Contabilitatea între tradiţional și modernism, Contabilitatea, expertiza și auditul afacerilor, $n r .10,19$.

Cătoiu, I. (coord.). (2009). Cercetări de marketing - tratat, București: Editura Uranus.

Ciuhureanu, A. T. (2014). Accounting policies manual between compulsoriness and necessity. study within entities in Centre Region, Annals of the University of Petroşani Economics, Vol. 14(2), 47-54.

Ciuhureanu, A. T. (2016). Accounting procedures between necessity and obligation for quality assurance in accounting, International Conference Knowledge-Based Organization. Vol. 22, issue 2, doi: 10.1515/kbo-2016-0044, available on-line at: https://www. degruyter.com/view/j/kbo.2016.22.issue-2/kbo-2016-0044/kbo-2016-0044.xml, 250-255.

Domokos, E. (1999). Management ieri, azi, mâine, Cluj-Napoca: Presa Universitară Clujeană, 171-172.

Nicolescu, O. \& Verboncu, I. (1999). Management, Bucureşti: Editura Economică, 249.

Ţugui, A. \& Ţugui, I. (2002). Profesioniştii contabili nu pot rămâne indiferenţi la evoluţiile din domeniul tehnologiilor informaţionale, Contabilitatea, expertiza şi auditul afacerilor, $n r .3,51$. 